\title{
Air ambulance missions to patients at locations not accessible by road - pleasant way to evacuate or advanced medicine in the field?
}

\author{
Andreas J Krüger*1,2 and Sindre Mellesmo ${ }^{1,2}$
}

\begin{abstract}
Address: ${ }^{1}$ Norwegian Air Ambulance Foundation, Drøbak, Norway and ${ }^{2}$ Dep. Of Anaesthesiology and Acute Care, St. Olavs Hospital, Norway
\end{abstract}
* Corresponding author

from Scandinavian Update on Trauma, Resuscitation and Emergency Medicine 2009

Stavanger, Norway. $23-25$ April 2009

Published: 28 August 2009

Scandinavian Journal of Trauma, Resuscitation and Emergency Medicine 2009, I7(Suppl 3):O28 doi:10.1 I86/I757-724I-I7-S3-O28

This abstract is available from: http://www.sjtrem.com/content/I7/S3/O28

(c) 2009 Krüger and Mellesmo; licensee BioMed Central Ltd.

\section{Introduction}

The air ambulance system in Norway is supposed to assist the critical ill or injured patient outside hospital. Indication for dispatch is urgent need for medical treatment or significant benefit in transport times to definitive care.

This service is also used for evacuation of patients at locations not accessible by road, and the indication for this practice has been debated.

In the current study we sought to investigate missions to patients at such locations.

\section{Methods}

Retrospective analysis of data from Dombås HEMS base in the period 1999-2008.

Patient characteristics, operational details and data on medical interventions were assessed and compared between the two sub-populations: those located at areas not accessible by road and those who were located at accessible sites. Chi-square and Mann-Whitney tests were used for statistical analysis for categorical and continuous data respectively.

\section{Results}

3659 missions were included in the analysis. Of these,

Table I: Patient and operational characteristics:

\begin{tabular}{lccc}
\hline Accessible by road & Yes & No & P-value for difference \\
\cline { 1 - 2 } Characteristic & & & \\
\hline & & & 0,15 \\
Age (mean, 95\% Cl) & & $45,2(43.7-46.8)$ & 0,03 \\
Gender (\% males) & $46,6(45.5-47.6)$ & 58,7 & 0,96 \\
Unit hour (median, range) & 63,5 & $1: 13(0: 10-12: 25)$ & $<0,001$ \\
On Scene Time (median, range) & $1: 28(0: 05-7: 57)$ & $0: 15(0: 00-7: 50)$ & $<0,001$ \\
NACA (median IQR) & $0: 19(0: 00-3: 12)$ & $3(2-4)$ & $<0,001$ \\
Summer & $4(2-6)$ & $22 \%$ & $11 \%$ \\
Winter & $78 \%$ & $10,4 \%$ & 0,88 \\
Anasthesia & $89 \%$ & & \\
\hline
\end{tabular}


Table 2: Preliminary diagnosis:

\begin{tabular}{lll}
\hline & Accessible by road & Not accessible by road \\
\hline Trauma & & \\
Cardiac & $40 \%$ & $62 \%$ \\
Muscular/skeletal & $30 \%$ & $13 \%$ \\
Endocrine & $0 \%$ & $4 \%$ \\
Nervous system & $1 \%$ & $1 \%$ \\
GI & $3 \%$ & $1 \%$ \\
Unclassified & $3 \%$ & $1 \%$ \\
\hline
\end{tabular}

606 missions were to locations not accessible by road. Results are presented in the Tables 1 and 2 below:

\section{Conclusion}

Patients located at non-accessible scenes are more often injured and female compared to our standard patient population. Median mission duration was shorter, but can occasionally very time-consuming. The fraction of patients receiving general anesthetics is the same in both groups, indicating the need for the anesthetist on-scene for a significant number of missions.

We conclude that our current practice of dispatch seems appropriate, but further studies on injury profile among patients located at places not accessible by road should be done.

Publish with Bio Med Central and every scientist can read your work free of charge

"BioMed Central will be the most significant development for disseminating the results of biomedical research in our lifetime. " Sir Paul Nurse, Cancer Research UK

Your research papers will be:

- available free of charge to the entire biomedical community

- peer reviewed and published immediately upon acceptance

- cited in PubMed and archived on PubMed Central

- yours - you keep the copyright

Submit your manuscript here:

http://www.biomedcentral.com/info/publishing_adv.asp 